\title{
The 'Anthropocene': a requiem for the Geologic Time Scale?
}

\author{
Valentí Rull \\ Institute of Earth Sciences Jaume Almera (ICTJA-CSIC), 08028 Barcelona, Spain \\ E-mail: vrull@ictja.csic.es
}

The Anthropocene Working Group (AWG) is finishing the proposal of the 'Anthropocene' as a formal epoch of the Geologic Time Scale (GTS), to be evaluated by the International Commission on Stratigraphy (ICS), with a deadline of 2016

(http://quaternary.stratigraphy.org/workinggroups/anthropocene/). The GTS is one of the main scientific achievements of humanity and is comparable to the periodic table of elements (Monastersky, 2015). Thus, any modification should be subjected to rigorous scrutiny (Finney \& Edwards, 2016). The proximity of the target date has caused discussions about the formalization of the 'Anthropocene' to intensify, as manifested in several reviews and essays that have been recently published in high-impact multidisciplinary journals, such as Nature and Science (Lewis \& Maslin, 2015; Ruddiman et al, 2015; Waters et al, 2016). The debate has focused on two main points, namely the convenience or not of formalizing a new epoch and the starting point of such eventual unit. However, the potential impact of any final decision on the GTS, as a whole, has not been addressed and is discussed here.

The concept of the 'Anthropocene' involves not only a new geochronologic unit but also a new state of the Earth System (ES), which is characterized by the global anthropogenic fingerprint. Therefore, this idea has transcended the field of geology and has been adopted in a wide range of ecological, environmental, sociological and philosophical disciplines. Some geologists believe that this has distorted 
the idea of the 'Anthropocene' as a geological unit (Hamilton, 2016) and has transformed the debate into a political, rather than scientific, issue (Finney \& Edwards, 2016). Few scholars question the global impact of human activities on the ES; however, the acceptance of the 'Anthropocene' as a formal geologic epoch is controversial (Monasterski, 2015; Ruddiman et al, 2015; Hamilton, 2015). Even the defenders of its formalization disagree about the onset of this new epoch (Waters et al, 2015; Ruddiman et al, 2015), which is a key issue in the definition of any new geochronologic/chronostratigraphic unit. It has also been debated whether we need to define a new human-dominated epoch or era, as the anthropogenic impact on the ES started at the beginning of the Holocene, while this epoch already captures our imprint on the biogeosphere (Ruddiman et al, 2015). However, the term 'Anthropocene' is already firmly rooted in the scientific and popular literature and is likely here to stay (Ruddiman et al, 2015). Thus, this term is likely to be generally used in a formal or informal fashion regardless of the final decision of the ICS (Monasterski, 2015).

The recent literature contains plenty of proposals, opinions and debates about this topic. However, beyond these discussions, there is a major issue that has not been properly addressed yet. If formalized, the 'Anthropocene' epoch may conclude the current GTS. This would be true not only for this term but also for any other with the prefix 'Anthropo-', such as the 'Anthropozoic' era proposed by Antonio Stoppani more than 140 years ago (Stoppani, 1873). Given the predicted magnitude and extent of anthropogenic influence on the ES (Williams et al, 2015), a new era might be more appropriate than a new epoch. However, to date, there is no a reliable criterion to determine the correct formal rank (era, period, epoch, age, etc.) for the potential new unit (Rull, 2016). Whatever the choice, any new geologic unit with the prefix 'Anthropo-' will persist until the disappearance of our species on Earth, at which point the GTS will no longer make sense. Humanity will not last forever (Rull, 2009), and continuing the current demographic and technological standards will likely impact the ES and the sedimentary record. An eventual return to an ES and a geologic record free from human influence would likely imply a dramatic demographic reduction and a deep cultural disruption, after which the continuity of the current GTS may not be guaranteed either. 
Therefore, in addition to fulfilling the standard criteria for the acceptance of a new unit, the ICS should consider whether the GTS as we know it should be capped by the 'Anthropocene' epoch and, consequently, by the Cenozoic era. The same would be true for the 'Anthropozoic' era, which has been surprisingly ignored, since the beginning, in the debate of the humanized ES and its geologic signature. Indeed, the initial proponents of the 'Anthropocene' (Crutzen \& Stoermer, 2000) mentioned Stoppani and his pioneering 'Anthropozoic' era but transformed the concept into an epoch without an explanation. In any case, if affirmative, the decision of closing the current GTS should be well substantiated for both present and future generations. Otherwise, future versions of the ICS may want to reopen the case and resurrect the prematurely-dead GTS. Accepting or not accepting the 'Anthropocene' as a formal geologic epoch may have paramount consequences for the current geologic framework. The AWG should address this issue in its final report, emphasizing the future of the GTS.

In summary, the problem is not as simple as formalizing or not formalizing the 'Anthropocene' as a new geologic epoch. Instead, we are facing a multi-faceted issue with mutually dependent answers. In addition to carefully analyzing the pros and cons of a new chronostratigraphic unit to designate the

geologic expression of the humanized ES, the ICS should consider questions as for example: what should be the geochronologic rank of such a unit? Should the new unit contain the prefix 'Anthropo-'? As a consequence, should we cap the current GTS with this new unit? These points must be thoroughly discussed for the ICS to provide a complete and unbiased decision.

\section{References}

Crutzen, P.J. \& Stoermer, E.F., 2000. The 'Anthropocene'. Global Change Newsletter 41, 17-18.

Finney, S.C. \& Edwards, L.E., 2016. The "Anthropocene" epoch: scientific decision or political statement? GSA Today 26, 4-10.

Hamilton, C., 2015. Getting the Anthropocene so wrong. The Anthropocene Review 2, 102-107. 
Hamilton, C., 2016. The Anthropocene as rupture. The Anthropocene Review, doi:10.1177/2053019616634741

Lewis, S.L. \& Maslin, M.A., 2015. Defining the Anthropocene. Nature 518, 171-180.

Monasterski, R., 2015. Anthropocene: the human age. Nature, 519, 144-147.

Ruddiman, W.F., Ellis, E.C., Kaplan, J.O. \& Fuller, D.Q., 2015. Defining the epoch we live in. Science 348, 38-39.

Rull, V., 2009. Beyond us. EMBO Reports 10, 1191-1195.

Rull, V., 2016. The humanized earth system. The Holocene, doi: 10.1177/0959683616640053

Stoppani, A., 1873. Corso di Geologia. Bernardoni Brigola, Milano.

Waters, C.N., Zalasiewicz, J., Summerhayes, C., Barnosky, A.D., Poirier, C. et al., 2016. The Anthropocene is functionally and stratigraphically distinct from the Holocene. Science 351 dx.doi.org/10.1126/science.aad2622.

Williams, M., Zalasiewicz, J., Haff, P.K., Schwärgel, C., Barnosky, A.D. \& Ellis, E.C., 2015, The Anthropocene biosphere. The Anthropocene Review 2, 196-219. 